\title{
Hiperparasitismo de Fusarium spp. em Austropuccinia psidii em Jambo-do-Pará
}

\author{
Vanessa Lopes Lira ${ }^{1} \oplus$, Ana Carla da Silva Santos ${ }^{1} \oplus$, Patricia Vieira Tiago ${ }^{1} \oplus$, Neiva Tinti de Oliveira ${ }^{1} \bullet$, \\ Romero Marinho de Moura ${ }^{1} \mathbb{B}$
}

\author{
${ }^{1}$ Universidade Federal de Pernambuco, Av. Prof. Moraes Rego, 1235, Cidade Universitária, CEP 50670-901 Recife, PE, Brasil. \\ Autor para correspondência: Vanessa Lopes Lira (vanessallira@yahoo.com.br) \\ Data de chegada: 08/11/2017. Aceito para publicação em: 25/02/2019.
}

$10.1590 / 0100-5405 / 187593$

\section{RESUMO}

Lira, V.L.; Santos, A.C.S.; Tiago, P.V.; Oliveira, N.T.; Moura, R.M. Hiperparasitismo de Fusarium spp. em Austropuccinia psidii em Jambo-doPará. Summa Phytopathologica, v.45, n.2, p.204-206, 2019.

Austropuccinia psidii é o agente etiológico de uma das principais doenças do jambeiro-do-pará: a ferrugem-amarela. Em uma ocorrência dessa doença foi constatada a ação de um fungo hiperparasito sobre uredossoro de A. psidii. A partir de folhas lesionadas, dois isolados de Fusarium foram caracterizados por análise morfológica e molecular. Os resultados revelaram que esses organismos pertencem a dois complexos de espécies: Fusarium fujikuroi (FFSC) e Fusarium solani (FSSC). A ocorrência desses fungos micoparasitas é uma forma de controle biológico natural para esta ferrugem e o seu estudo contribuirá para o manejo da ferrugem amarela.

Palavras-chave: controle biológico, ferrugem amarela, Fusarium concentricum, Fusarium solani, micoparasitismo.

\section{ABSTRACT}

Lira, V.L.; Santos, A.C.S.; Tiago, P.V.; Oliveira, N.T.; Moura, R.M. Hyperparasitism of Fusarium spp. in Austropuccinia psidii in “Jambo-do-Pará". Summa Phytopathologica, v.45, n.2, p.204-206, 2019.

Austropuccinia psidii is the etiologic agent of one of the major diseases affecting "jambeiro-do-pará": yellow rust. During the incidence of yellow rust, the action of a hyperparasitc fungus on uredosore of $A$. psidii was observed. From injured leaves, two Fusarium isolates were characterized based on morphological and molecular analysis. Results evidenced that these organisms belong to two species complexes: Fusarium fujikuroi (FFSC) and Fusarium solani (FSSC). Occurrence of these mycoparasite fungi is a form of natural biological control for this rust and the study of these fungi will contribute to the management of yellow rust.

Keywords: biological control, yellow rust, Fusarium concentricum, Fusarium solani, micoparasitism.

Syzygium malaccense (L.) Merryl \& Perry, também conhecida por jambeiro-do-pará, é uma planta arbórea e frutífera, pertencente à família Myrtaceae, com potencial ornamental e terapêutico, por apresentar atividades antiinflamatória, antioxidante e diurética (6). Uma das principais doenças do jambeiro-do-pará é a ferrugem amarela, causada por Austropuccinia psidii (G. Winter) Beenken, (anteriormente Puccinia psidii) um fungo biotrófico, patogênico a diversas espécies de Myrtaceae de importância comercial. A principal característica da doença é a formação de pústulas amarelas nas folhas, de formato irregular (7). Essas lesões (uredossoros), estabelecidas em folhas e caules em estádio de desenvolvimento, afetam os processos fisiológicos do hospedeiro (3).

Os principais métodos de controle das ferrugens consistem na remoção e destruição das partes afetadas do hospedeiro, uso de genótipos resistentes, aplicações de fungicidas e controle biológico, sendo que para o patossistema $S$. malaccens / A. psidii não há dados de controle pertinentes e o controle biológico se apresenta como alternativa (3). Em uma ocorrência da ferrugem do jambeiro-do-pará, com alta severidade, foi observada a correlação entre a paralisação da evolução das lesões da ferrugem e o desenvolvimento superficial de um micélio fúngico sobre uredossoros. Os objetivos do trabalho foram reportar a ação antagônica de Fusarium spp. sobre A. psidii e caracterizar dois isolados por meio de marcadores morfológicos e moleculares.

O material analisado foi proveniente de Reserva de Mata Atlântica,
Camaragibe, Pernambuco, Brasil (7 59' 24,92" S e 34 58' 6,94” W). Folhas do jambeiro-do-pará contendo lesões da doença foram submetidas a condições de câmara úmida, por $48 \mathrm{~h}$. Em seguida, propágulos do fungo desenvolvidos sobre uredossoros foram transferidos para placas de Petri, contendo meio de cultura batata-dextrose-ágar (BDA) e após cinco dias de incubação em câmara BOD a $28{ }^{\circ} \mathrm{C}$, as colônias foram purificadas. De cinco isolados obtidos, dois foram selecionados, por apresentarem características macromorfológicas distintas.

Para a caracterização macroscópica, discos de $0,5 \mathrm{~cm}$ de micélio foram transferidos para placas de Petri contendo meio BDA, incubadas em câmara BOD a $25^{\circ} \mathrm{C}$, no escuro. Foram avaliadas três repetições. O diâmetro das colônias foi mensurado diariamente, até o quarto dia, e a coloração do micélio e reverso da placa foi avaliada após sete dias. Para a caracterização microscópica, 30 unidades de cada estrutura foram medidas, como: conídios, clamidósporos e fiálides, a partir de colônias crescidas em meio SNA (synthetic nutrient-poor agar), após 10 dias de incubação a $25^{\circ} \mathrm{C}$ e fotoperíodo de $12 \mathrm{~h}$. Para a identificação molecular, foi realizado o sequenciamento da região $T E F-1 \alpha$ do DNA (4). As sequências obtidas foram comparadas com sequências contidas do Banco de Dados Fusarium MLST, por meio da ferramenta básica de pesquisa de alinhamento local (BLAST).

As lesões decorrentes de $A$. psidii eram severas e presentes apenas nas folhas novas (Figura 1A e 1D). Observou-se correlação entre a paralisação da evolução das lesões da ferrugem e o desenvolvimento do 
micélio do hiperparasito (Figura 1B e 1C). Observações microscópicas em exame direto de lesões mostraram que fungos similares ao gênero Fusarium estavam associados às lesões.
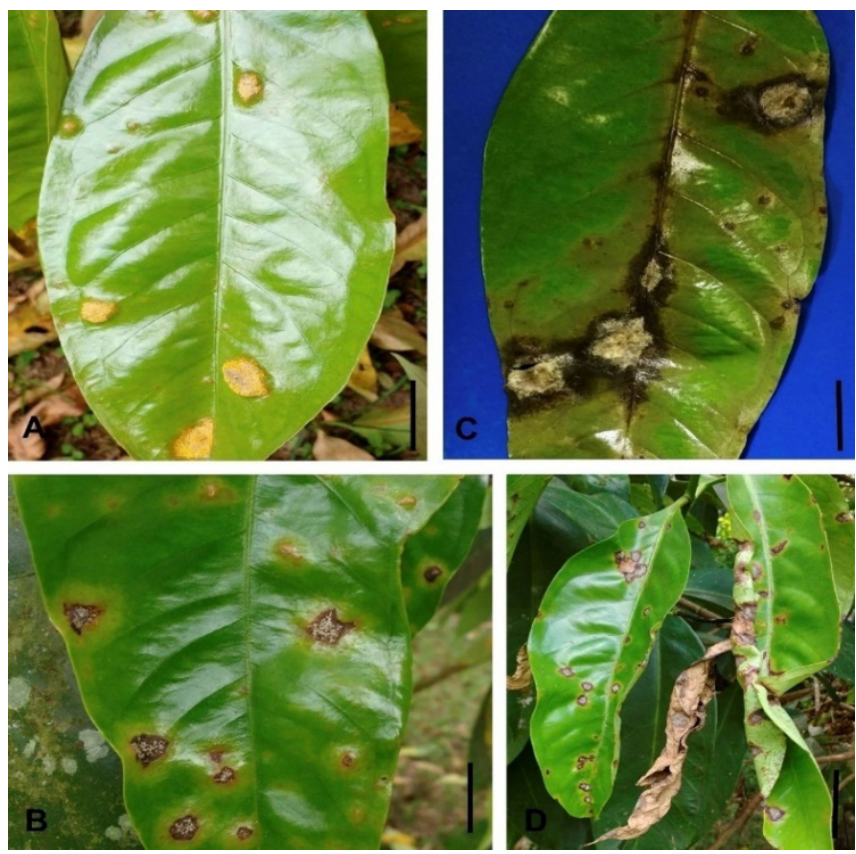

Figura 1. A) Folhas de jambo-do-pará apresentando uredossoros não hiperparasitadas; Barra $=2 \mathrm{~cm}$. B) Lesões apresentando halo amarelo e indícios do hiperparasitismo; Barra $=2 \mathrm{~cm}$. C) Presença de micélio branco sobre as lesões causadas por $A$. psidii. Barra $=2 \mathrm{~cm}$. D) Folhas apresentando lesões hiperparasitadas; Barra $=5 \mathrm{~cm}$.

As espécies hiperparasitas de $A$. psidii foram identificadas como pertencentes aos complexos de espécies Fusarium fujikuroi (FFSC) e Fusarium solani (FSSC). O isolado do FFSC correspondeu com 99,52\% de similaridade a espécie Fusarium concentricum Nirenberg \& O'Donnell e o isolado FSSC apresentou 99,26\% de similaridade com uma espécie identificada por FSSC 27. Esta espécie foi resultante de estudos de filogenia molecular e ainda não foi descrita morfologicamente (8).

$\mathrm{O}$ isolado de $F$. concentricum apresentou colônias de coloração cinza a cinza-branco, com o centro da colônia roxo acinzentado e reverso fuscous black, e taxa de crescimento de $11,6 \mathrm{~mm} / \mathrm{dia}$. Macroconídios falcados, com $20-(30,4)-40 \mu \mathrm{m}$ de comprimento e 3 - 5 septos (Figura 2B), e microconídios clavados, obovóides a piriformes, $0-1$ septo, zero na grande maioria (Figura $2 \mathrm{C}$ ), produzidos sobre falsas cabeças (Figura 2A). Clamidósporos ausentes. O isolado de FSSC 27 apresentou colônias de coloração quase branca, com o centro cinzento arroxeado à cinza vináceo e reverso vináceo escuro, e taxa de crescimento de $11,7 \mathrm{~mm} /$ dia. Macroconídios falcados, (Figura 2E), com 20 -(27,9)-37,5 $\mu \mathrm{m}$ de comprimento e 1-3 septos, e microconídios ovais ou obovóides com a base truncada, $0-1$ septo (Figura 2F), produzidos sobre falsas cabeças em fiálides relativamente longas (Figura 2D). Clamidósporos não observados.

Membros do FFSC são responsáveis por doenças em plantas de importância comercial e também pela produção de micotoxinas (5). O complexo FSSC também compreende patógenos de diversas plantas e espécies causadoras de doença em humanos e em outros animais (8). No entanto, embora as espécies de Fusarium sejam conhecidas principalmente como causadoras de doenças em plantas, a investigação de Fusarium em plantas e solo de áreas com baixa perturbação sugere que o número de espécies não associadas a doenças de plantas pode superar as fitopatogênicas (9).

Até o momento, não há registros de $F$. concentricum e de espécies do complexo $F$. solani parasitando A. psidii; portanto, este deve ser o primeiro. Amorim et al. (1) relataram a ocorrência de Fusarium decemcellulare infectando A. psidii em goiabeira (Psidium guajava L.) e observaram redução de $70 \%$ do número de uredósporos viáveis em testes de parasitismo. De acordo com Carling et al. (2), esse controle
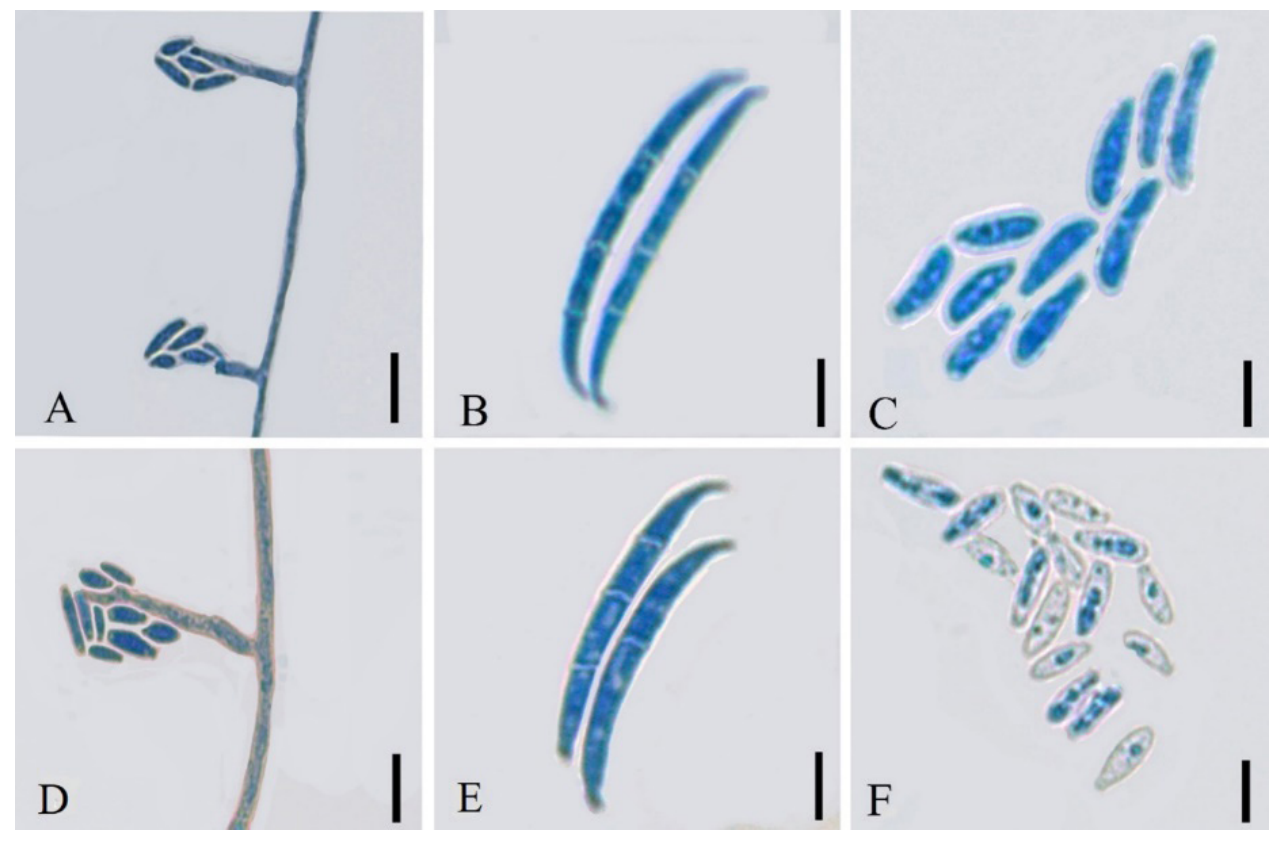

Figura 2. Fusarium concentricum (A-C). A) Microconídios sobre falsas cabeças; Barra $=10 \mu \mathrm{m}$. B) Macroconídios falcados; Barra = $10 \mu \mathrm{m}$. C) Microconídios obovoides e piriformes; Barra $=6 \mu \mathrm{m}$. Fusarium solani. (D-F). D) Microconídios sobre falsas cabeças; barra $=8 \mu \mathrm{m}$. E) Macroconídios falcados; Barra $=8 \mu \mathrm{m}$. F) Microconídios obovoides e piriformes. Barra $=10 \mu \mathrm{m}$. 
biológico pode ocorrer por meio da penetração nos uredósporos por hifas não especializadas e, também, pela degradação enzimática produzido pelo micoparasita. O registro destas duas espécies de Fusarium parasitando uredósporos de $A$. psidii pode motivar estudos sobre a viabilidade de uso destes hiperparasitos em controle biológico da ferrugem amarela.

\section{AGRADECIMENTOS}

À Fundação de Amparo à Ciência e Tecnologia de Pernambuco (FACEPE) e ao Conselho Nacional de Desenvolvimento Científico e Tecnológico $(\mathrm{CNPq})$ pelo auxílio financeiro.

\section{REFERÊNCIAS}

1. Amorim, E.P.R.; Pio-Ribeiro, G.; Menezes, M.; Coelho, R.S.B. The pathogenicity and hyperparasitic action of Fusarium decemcellulare on Puccinia psidii in guava (Psidium guajava). Fitopatologia Brasileira, v.18, n. 2, p.226-229, 1993.

2. Carling, D.; Brown, M.; Millikan, D. Ultrastructural examination of the Puccinia graminis-Darluca filum host-parasite relationship. Cytology and Histology, v.66, n. 4, p.419-422, 1976.
3. Glen, M.; Alfenas, A.C.; Zauza, E.A.V.; Wingfield, M.J.; Mohammed, C. Puccinia psidii: a threat to the Australian environment and economy - a review. Australasian Plant Pathology, v. 36, n. 1, p. 1-16, 2007.

4. Griffiths, R.; Whiteley, A.S.; O'Donnell, A.G., Bailey, M.J. Rapid Method for Coextraction of DNA and RNA from Natural Environments for Analysis of Ribosomal DNA and rRNA-Based Microbial Community Composition. Applied And Environmental Microbiology, vol. 66 n. 12, p. 5488-5491, 2000.

5. Kvas, M.; Marasas, W.F.O.; Wingfield, B.D.; Wingfield, M.J.; Steenkamp, E.T. Diversity and evolution of Fusarium species in the Gibberella fujikuroi complex. Fungal Diversity, v. 34, p. 1-21, 2009.

6. Melo, R.R.; Araújo, E.R.S.; Silva, A.A.L.; Randau, K.P.; Ximenes, E.C.P.A. - Características farmacobotânicas, químicas e biológicas de Syzygium malaccense (L.) Merr. \& 1. M. Perry. Revista Brasileira de Farmácia, v. 90, n. 1, p. 298-302, 2009.

7. Morin, L.; Aveyard, R.; Lidbetter, J.; Wilson, P.G. Investigating the hostrange of the rust fungus Puccinia psidii sensu lato across tribes of the family Myrtaceae present in Australia. PLoS ONE, v. 7, n. 4, p. e35434, 2012.

8. O’Donnell, K.; Sutton, D. A.; Fothergill, A.; Mccarthy, D.; Rinaldi, M. G.; Brandt, M. E.; Zhang, N.; Geiser, D. M. Molecular phylogenetic diversity, multilocus haplotype nomenclature, and in vitro antifungal resistance within the Fusarium solani species complex. Journal of Clinical Microbiology, v. 46, n. 8, p. 2477-2490, 2008.

9. Summerell, B. A.; Leslie, J. F. Fifty years of Fusarium: how could nine species have ever been enough? Fungal Diversity, v. 50, p. 135-144, 2011. 